Research Article

\title{
Research on Tunnel Surrounding Rock Failure and Energy Dissipation Based on Cyclic Impact and Shear Loading
}

\author{
Yu Ding, ${ }^{1,2,3}$ Zhuoying Tan $\mathbb{D}^{1,},{ }^{1,2,3}$ Shuguang Li $\mathbb{D}^{4,5}$ Runke Huo ${ }^{4}{ }^{5}$ Ziliang Liu, ${ }^{1,2,3}$ \\ and Yong $\mathrm{Ma}^{1,2,3}$ \\ ${ }^{1}$ School of Civil and Resource Engineering, University of Science and Technology Beijing, Beijing 100083, China \\ ${ }^{2}$ Beijing Key Laboratory of Urban Underground Space Engineering, University of Science and Technology Beijing, \\ Beijing 100083, China \\ ${ }^{3}$ State Key Laboratory of High-Efficient Mining and Safety of Metal Mines, University of Science and Technology Beijing, \\ Beijing 100083, China \\ ${ }^{4}$ Post-doctoral Research Workstation, China Railway 20th Bureau Group Co., Ltd., Xi'an 710016, China \\ ${ }^{5}$ School of Civil Engineering, Xi'an University of Architecture and Technology, Xi'an 710055, China
}

Correspondence should be addressed to Zhuoying Tan; markzhy_tan@163.com and Shuguang Li; lssgg2015@163.com

Received 24 September 2020; Revised 18 January 2021; Accepted 15 June 2021; Published 23 June 2021

Academic Editor: Jian Ji

Copyright $(2021$ Yu Ding et al. This is an open access article distributed under the Creative Commons Attribution License, which permits unrestricted use, distribution, and reproduction in any medium, provided the original work is properly cited.

\begin{abstract}
Aiming at the cyclic impact deformation and failure of tunnel surrounding rock under shear stress, a self-developed rotationimpact simulation test platform was used to determine the number of failures, stress-strain curves, and energy in the process of cyclic impact failure. The failure process of rock under different impact velocities and shear stresses has been systematically studied. Results show that, under the same impact speed, the shear stress will increase with the increase in the rotation speed, but an upper limit will exist. When the rotation speed reaches this upper limit, the shear stress will no longer increase. The presence of shear stress will reduce the number of impacts required for rock failure. When the impact speed is $7.2 \mathrm{~m} / \mathrm{s}$, the number of impacts at the maximum rotation speed is $60 \%$ of the static state. When the impact velocity is $16.8 \mathrm{~m} / \mathrm{s}$, this value is only $33.3 \%$. At the same impact velocity, the stress-strain curves under different rotation speeds do not change significantly, but with the increase in the rotation speed, the slope of the elastic stage of the stress-strain curve gradually decreases, and the corresponding stress of the rock sample decreases when the maximum strain is reached. With the increase in shear stress, the crushing specific energy required for rock failure gradually decreases. The greater the impact velocity, the more obvious the impact of shear stress on energy dissipation. In the tunnel process, when the surrounding rock is subjected to impact loads from different directions, only the axial strain analysis will have certain safety hazards, and timely support and reinforcement work are required.
\end{abstract}

\section{Introduction}

With the development of various types of large-scale geotechnical engineering, tunnel engineering is being increasingly applied in different fields, such as in large-section railways, underground transportation systems, highway tunnel construction, and mining transportation tunnels. However, due to blasting excavation disturbance, safety issues such as tunnel deformation, instability, and surrounding rock damage caused by high ground stress have always been a hot spot in tunnel engineering research [1-4].
Blasting is widely used in tunnels and other geotechnical engineering projects because it is economical, efficient, and fast. Part of the energy generated by explosives during blasting excavation is used to strip the rock mass to achieve the purpose of engineering excavation. Another part of the energy is transferred to the surrounding rock mass in the form of blasting shock wave, causing a certain degree of damage and destruction to the surrounding rock mass, thereby causing safety hazards to the tunnel surrounding the rock engineering project $[5,6]$. For the middle and far areas away from the blasting source, although the stress wave 
generated by one blasting is not strong enough to cause direct damage to the rock mass, it will cause the natural cracks in the rock to propagate and extend. Under the repeated action of the stress wave, the number and length of the internal cracks in the rock continue to increase, gradually connecting, penetrating, and forming the main crack. The internal damage of the rock evolves and develops in a nonlinear cumulative manner and eventually leads to loosening and slippage of the structural surface. Many engineering examples have proved that even buildings far away from the blasting operation point will also experience collapse, deformation, and instability $[7,8]$. Rock is a brittle material with multiple internal cracks, which have obvious anisotropy. Different loading methods and directions will lead to different failure modes. For example, in a natural environment, when the in situ stress and other static loads are low, the original cracks inside the rock will close, and the development of cracks will be restricted when damaged by impact loads. The rock has a strong ability to resist damage. But when the static load exceeds a certain range, the crack inside the rock is almost at the stage of breaking through, and the rock's antidestructive ability is weak. Research shows that, under the action of the same stress wave, different incident angles at the crack will result in different reflected waves and failure laws, which will affect the failure laws of rocks and the transfer of stress wave energy [9]. Given the perturbation and damage of tunnels and another geotechnical engineering under cyclic loading during blasting and excavation and during normal use, many scholars have conducted in-depth studies on the mechanical properties, failure laws, and damage evolution of rocks under static cyclic loading. For the research of tunnel deformation and tunnel safety, numerical simulation is a convenient, profitable, and quick method; many scholars have conducted very comprehensive studies [10-13]. Combining with the engineering site, Ağbay and Topal [14] found that the ground settlement caused by double tunnel engineering mainly depends on the deformation modulus of surrounding rock and soil through field monitoring and numerical simulation methods, and a new formula for predicting ground deformation caused by double tunnel engineering is proposed. Singh [15] aimed at the impact and vibration damage of nearby open-pit blasting to underground coal mines; the borehole extensometers and strain and stress sensors arranged on the roof and pillars were used to monitor the vibration and deformation of the ground before and after the blasting. Sharma et al. [16] studied the effect of large-scale excavation on the deformation of adjacent rapid transit tunnels through various monitoring methods, and the results showed that the stiffness of the tunnel lining has a greater impact on the deformation and damage of the tunnel caused by the adjacent excavation. The research on the characteristics of tunnel surrounding rock is mainly carried out through the indoor impact test. Li et al. [17] studied the dynamic mechanics of the noncontinuous jointed rock model under cyclic dynamic loading and found that the deformation modulus of the jointed rock mass increases with the increase of the loading frequency, and the irreversible deformation increases with the number of cycles.
It increases and decreases as the loading frequency increases. Experimental research by Bagde and Petro [18] showed that the dynamic fatigue strength, dynamic axial stiffness, and dynamic modulus of rock are related to the frequency and amplitude of the load. Liu and He [19] used the MTS-815 testing machine to conduct cyclic test research on sandstone specimens under different confining pressures. The results showed that confining pressure has a greater impact on the mechanical properties of rocks under cyclic loading; axial strain and irreversible volume strain increase when the rock fatigue damages with the increase of pressure. Li and $\mathrm{Ma}$ [20] used two cylindrical granite cores to make the incident rod and the transmission rod, respectively, sandwiched between the two soil layers of different thickness and water content to simulate the filling in the joint and used a pendulum to impact the incident rod. They provided stress wave, used stress wave separation technology to obtain the stress-strain curve in the impact process, and studied the influence of fillings on the dynamic mechanical properties of joints. The fatigue deformation and strength degradation of rock under cyclic loading are mainly reflected in the incubation, propagation, and penetration of internal microcracks. To evaluate the development of rock damage, it is necessary to define its damage variables reasonably. According to the observed size, the damage variables can be determined from the microscopic, mesoscopic, and macroscopic perspectives. The microangle is mainly carried out from the material's atomic or molecular point of view. At present, it is difficult to observe the exchange process of atoms and molecules under cyclic loading. Therefore, rock damage is mainly defined by mesoscopic and macroscopic perspectives [21]. Many scholars have tried to define rock damage variables in the mesoperspective and macroperspective. At present, the more mature methods mainly include CT scanning method [22], acoustic wave velocity method [23], acoustic emission method [24], resistivity method [25], and energy method [26].

For the dynamic response of tunnel surrounding rock subjected to impact load, many scholars at home and abroad have studied it from the perspective of theoretical analysis, test, and numerical simulation. As early as 1984, Dowding [27] studied the problem of tunnel rock damage through the blasting test and found that the compressive wave strain caused by the explosion can be equivalent transformed into seismic shear strain and surface wave strain, and the tunnel rock strain can be used as a basic index to judge tunnel damage. Since then, more and more attention has been paid to the tunnel safety problems caused by the explosion, and the research on tunnel vibration monitoring and deformation control has gradually formed a discipline [28]. Zhao et al. [29] carried out a rock dynamics study on the excavation of an ammunition depot cavern in Singapore and systematically studied the dynamic characteristics of rocks with different materials, the dynamic shear characteristics of rock joints, and the influence mechanism of the rock structure on the dynamic response, which provided the necessary basis for the design and construction of the cavern project. Chen et al. [30] used the discrete element software UDEC to simulate the propagation process of the explosion 
stress wave in the underground rock mass, and compared with the empirical formula calculation and field test results, it was found that UDEC can simulate the propagation process of the explosion shock wave in rock, and the results have high reliability. Hao et al. [31] studied the influence of rock joints on stress wave propagation by adjusting the angle between rock joints and rock surface and gave the peak attenuation, frequency spectrum, and spatial variation law of the stress wave. Zhou and Jenssen [32], from the perspective of explosive storage safety distance, studied the damage law of the adjacent cabin in case of an accidental explosion and proposed the separation principle of underground storage facilities according to the investigation report and test results of tunnel damage. Deng et al. [33] and Zhao et al. [34] used a numerical simulation method to analyze the damage of the tunnel under the action of the explosion shock wave. The results show that rock joints have a great influence on tunnel damage, while the initial stress of the rock mass has little effect. Through bolt support, particle velocity can be changed to improve tunnel stability. Zhu et al. [35] analyzed the failure law of rock under the action of the explosion shock wave by the finite element analysis method. The results show that the peak particle velocity (PPV) increases with the increase of explosive density and with the decrease of distance from the explosion source. With the increase of the rock joint dip angle, PPV first decreases and then increases sharply. With the increase of joint spacing, PPV first increases and then keeps stable. The research results are of great significance to engineering design and support.

The foregoing analysis shows that there have been many studies on tunnel deformation and fatigue damage of tunnel surrounding rock masses under cyclic loading. There are three main methods for these studies. The first method is to guide tunnel projects under construction based on the experience and results of previous project site analysis. For example, urban underground projects such as subways and underground pipe networks have many reference cases [36-38]. The second method is to use the method of simulation test in the laboratory to study the damage, failure process, and related laws of the rock under different load conditions through various rock mechanics testing machines or design experiments. This is also the current research result. It is one of the most common methods, but the disadvantage of this method is that it loses the constraints of the natural environment, and its results have certain limitations. The third method is through a variety of computer simulation software. This method is a new method that has emerged with the development of computer technology in recent years. It has the advantages of a good economy, wide application range, and visualization of the analysis process. The above research methods are mainly devoted to solving two problems in underground geotechnical engineering. The first is the impact of blasting impact and nearby engineering excavation on existing engineering such as underground tunnels and caverns. The main factors affecting the deformation and failure of tunnel surrounding rock and their occurrence mechanism are determined through the aforementioned research methods. The second is to carry out corresponding support and stability studies for the failure mechanism of surrounding rocks to solve the safety problems encountered in the project. In laboratory tests aimed at this direction, scholars mainly simulate the failure mechanism of rocks in different environments by changing the conditions of rock loading, such as applying external loads such as axial pressure and confining pressure to the rock mass to be tested or changing the temperature and water content. This article is also carried out based on this research idea. In actual engineering, the impact of blasting generated in different directions will cause the rock mass to be superimposed on impact loads of different angles, which will cause shear strain in the rock and make the failure process of the rock more complicated. Under the rotation-impact cyclic load, no relevant research results are available as to what kind of failure law the rock will show and how the stress-strain relationship, damage variable, energy absorption, impact force, and rotation speed are related. Because of the above problems, this paper will use the self-developed impact dynamics simulation test bench to systematically study the rock failure process under the action of cyclic rotating impact.

\section{Introduction of Rotation-Impact Experiment Scheme}

2.1. Rotation-Impact Simulation Test Bench. As the most widely used test device in geotechnical engineering impact tests, the Hopkinson bar was invented by Bertram Hopkinson in 1914, to measure the transmission effect of stress waves in metal bars. At present, the widely used device in the stress wave impact test is the split Hopkinson pressure bar (SHPB) designed by Kolsky in 1949, which can impose an impact load with a certain strain rate on the specimen. The device is mainly composed of a launch system, test rod system (including incident rod and reflector rod), and data monitoring system. By pasting high-sensitivity strain gauges on the incident rod and the reflecting rod, the stress waves on the incident rod and the transmission rod can be obtained, and the dynamic stress, strain, and strain of the specimen clamped between the two pressure rods can be obtained by indirect methods. Through this method, the difficulty and uncertainty of data capture encountered indirect measurement can be effectively avoided [39]. The device is simple to operate, ingenious in testing methods, and can be modified for different research needs.

The dynamic simulation test bed used in this article is a rotation-impact simulation device jointly designed and developed by the University of Science and Technology Beijing and the University of Toronto based on the split Hopkinson pressure bar. The test bed is mainly composed of high-precision test platform, test rod system, launch system, rotation system, and data acquisition system. The schematic diagram and physical diagram of the test bed are shown in Figures 1 and 2. The working process of the test bed is as follows: the cylinder in the launch system is set to a certain air pressure value so that the impact rod will rush out of the launch pipe under the action of gas and hit the tail of the drill pipe in the test rod system at a certain speed. At this time, the drill pipe will gain a certain speed, and then, the drill bit at 


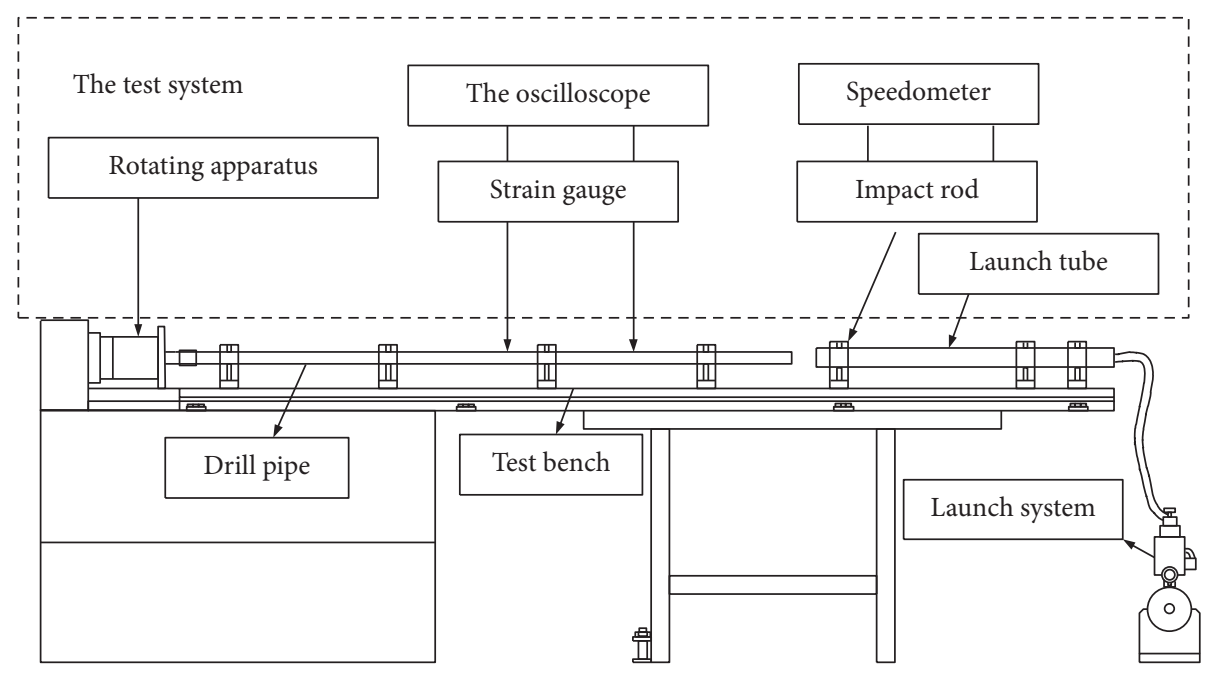

FIGURE 1: Schematic diagram of the rotation-impact simulation system.

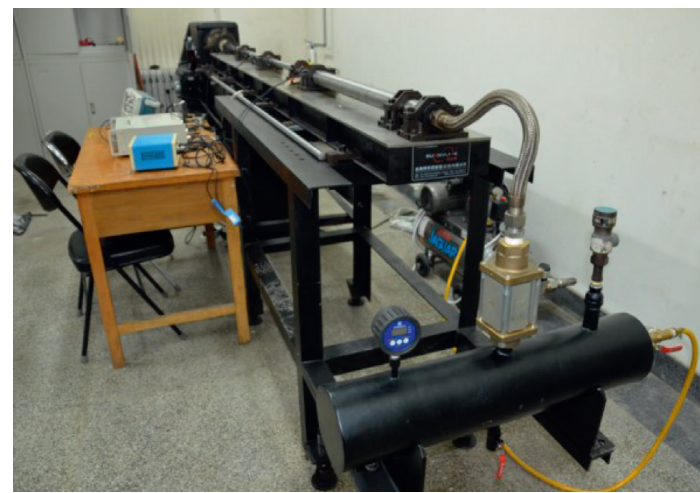

FIgURE 2: Physical drawing of the rotation-impact simulation system.

the end of the drill pipe impacts the rotating rock sample under the control of the rotating system, thus completing a complete rotating impact process.

Compared with the split Hopkinson rod, this test bed retains the launch system, the test rod system (only the incident rod, that is, the drill rod), the data monitoring system, and the new rotation system. The modified test bench can keep the rock mass to be tested constantly at the preset rotation speed. When the drill pipe contacts the rock to be tested, a set of shear stress waves will be generated, and the shear stress waves can pass through the contact surface. The drill pipe (measured by the shear strain gauge installed on the drill pipe) and the internal transmission of the rock, the shear stress wave transmitted to the rock part, and the incident wave will cause damage to the rock together. While retaining the advantages of the separated Hopkinson pressure bar, such as convenient operation, the test bench also adds a shear stress wave with a controllable value. By controlling the equipment to superimpose the shear stress wave and the conventional incident stress wave, it is possible to explore the cyclic impact failure law of the rock under the action of shear stress. However, because the rock to be tested is rotating, the test rig lacks the transmission rod part, and the size of the transmitted wave cannot be directly measured, and a reasonable conversion is required in the energy calculation process. In this paper, the stress homogenization assumption will be used for calculation, that is, the stress generated at the two ends of the rock sample during the impact is equal, and the transmitted wave can be derived from the reflected wave [40-43].

The impact rod and drill pipe of the test bed are made of high-strength steel, with a density of $7850 \mathrm{~kg} / \mathrm{m}^{3}$, the elastic modulus of $210 \mathrm{GPa}$, and shear modulus of $90 \mathrm{GPa}$. The diameter of both rods is $25 \mathrm{~mm}$, the length of the impact rod is $200 \mathrm{~mm}$, and the length of the drill pipe is $1800 \mathrm{~mm}$. PDC bit is selected for this test, with an inner diameter of $25 \mathrm{~mm}$ and the outer diameter of $35 \mathrm{~mm}$.

2.2. Test Equipment and Principle. During the test, the data acquisition instruments mainly include CS-1D dynamic resistance strain gauge, DPO2014B mixed signal oscilloscope, MTTU microsecond time detector, and digital electromagnetic tachometer. The actual device diagram is shown in Figure 3. The CS-1D dynamic resistance strain gauge adopts electronic automatic balance technology. It is an ultradynamic high-performance automatic balance strain gauge (frequency range is $0-1 \mathrm{MHz}$ ). It is equipped with different types of strain gauges and strain gauge sensors. It can realize the measurement of stress, tensile pressure, speed, acceleration, displacement, torque, and other physical quantities. The DPO2014B digital oscilloscope provides $100 \mathrm{MHz}$ bandwidth and $1 \mathrm{GS} / \mathrm{s}$ sampling rate. Waveform capture frequency is 5000 per second. The variable low-pass filter is used to stop unnecessary noise and still display high-frequency events. Using infrared detection technology, the MTTU microsecond time detector can accurately measure the microsecond level of high-speed motion process. The impact speed of the drill pipe can be calculated by calibrating the distance between two infrared laser beams. In the drop weight, SHPB, and 


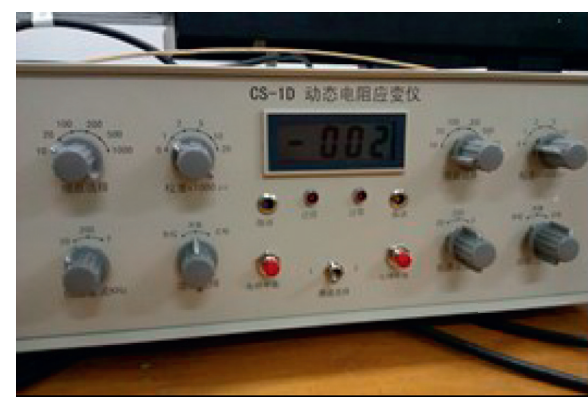

(a)

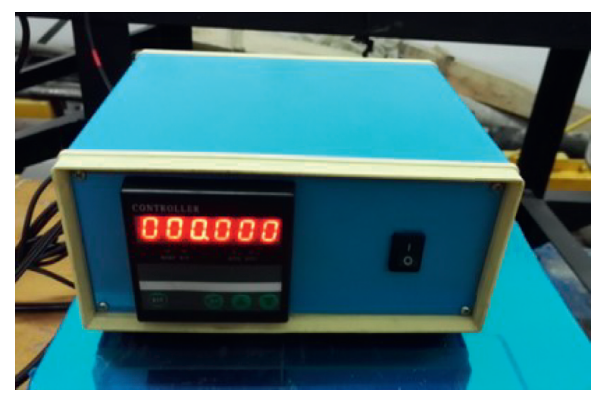

(c)

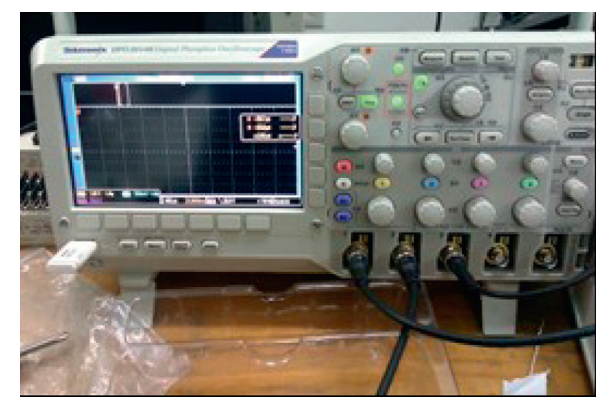

(b)

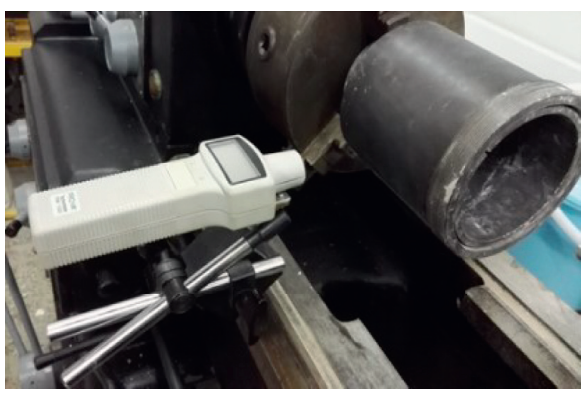

(d)

Figure 3: Physical drawing of test equipment. (a) Dynamic resistance strain gauge. (b) Oscilloscope. (c) Microsecond chronograph. (d) Electromagnetic tachometer.

other tests, the final speed can be used as a controllable parameter in the impact test after the final speed is measured. The digital electromagnetic tachometer can measure accurately without contacting the rotating system, and the range of speed measurement is from $2 \mathrm{rpm}$ to $9999 \mathrm{rpm}$.

\subsection{Stress Wave Propagation Process of the Test Platform.} In the deformable solid medium, the disturbance to the mechanical equilibrium state is manifested in the change in the particle velocity and the corresponding change of the stress and strain state. The disturbance caused by stress and strain propagates in solid at a certain speed in the form of a wave, which is called a stress wave. Before the start of the test, a reserved width $d$ should be set between the drill pipe and the rock sample to be tested. When the impact rod collides with the drill pipe, the incident stress wave will be generated inside the drill pipe, and then, the incident wave will reflect on the contact surface of the drill pipe and the rock sample to form a tensile wave. When the incident wave is completely reflected, the reserved width is closed. Therefore, the reserved width is the displacement of the impact end of the impact rod when the impact rod impacts the knot. The velocity of the stress wave generated in the impact of the equal diameter rod is related to the inherent characteristics of the rod material (elastic modulus and density) but not to the length of the drill pipe. Therefore, when the impact rod of length $L_{0}$ collides symmetrically with the drill pipe at the impact velocity $V_{0}$, the particle velocity in the drill pipe after the wave is $v=V_{0} / 2$, and the incident wave width is $\tau=2 L_{0} / c_{0}$. Therefore, the calculation formula for the reserved width $d$ and wave speed $c_{0}$ is

$$
\begin{aligned}
d & =v t, \\
& =\frac{L_{0} V_{0}}{\mathrm{c}_{0}}, \\
c_{0} & =\sqrt{\frac{E_{0}}{\rho_{0}}}
\end{aligned}
$$

where $c_{0}$ is the stress wave velocity, $E_{0}$ is the elastic modulus of the drill pipe, and $\rho_{0}$ is the drill pipe density.

The first reflected wave $\varepsilon_{r 1}$ is reflected at the loading end to form a secondary impact loading $\varepsilon_{i 2}$. When the secondary loading stress wave reaches the drill bit, the drill bit and the sample only touch. At this time, because the rock sample is rotating at high speed, the compression wave generated by the impact is reflected to form compression wave $\varepsilon_{r 2}$ and shear wave $\gamma$. The system wave diagram is shown in Figure 4.

\subsection{Calculation and Analysis of Related Parameters in Impact} Process. The stress wave of the rotation-impact system is monitored by a strain gauge attached to the drill pipe. When the stress wave passes through the drill pipe, the strain caused will cause a voltage change. The strain value can be calculated through the principle of the Wheatstone bridge, and then, the material stress-strain relationship can calculate the stress value at different moments.

According to the Wheatstone bridge principle and oscilloscope parameter setting, the calculation formulas of axial strain $\varepsilon(t)$, shear strain $\gamma(t)$, and display voltage are as follows: 


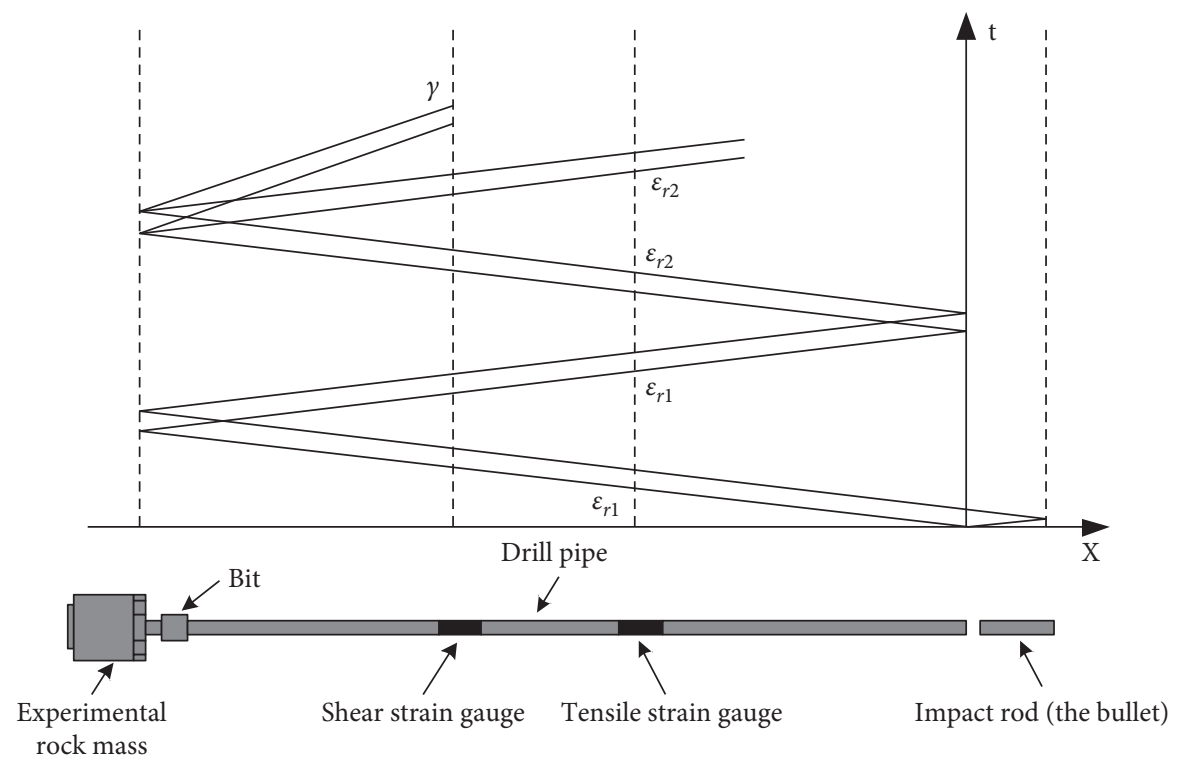

FIgURE 4: Experimental device and wave system.

$$
\begin{aligned}
\mathcal{E}(t) & =\frac{1}{2} \frac{2}{U_{0}} \frac{2.0}{k_{1}} \frac{U_{x 1}}{K_{2}}, \\
& =\frac{2 U_{x 1}}{U_{0} K_{1} K_{2}}, \\
\gamma(t) & =\frac{1}{2} \frac{2}{U_{0}} \frac{2.0}{k_{1}} \frac{U_{x 2}}{K_{2}}, \\
& =\frac{2 U_{x 2}}{U_{0} K_{1} K_{2}},
\end{aligned}
$$

where $U_{0}$ is the bridge voltage (take $4 \mathrm{~V}$ ), $U_{x}$ is the voltage displayed by the oscilloscope $\left(U_{x 1}\right.$ and $U_{x 2}$ are the voltage changes caused by tension and compression strain and shear strain, respectively), $K_{1}$ is the strain gauge sensitivity coefficient (take 2.00), and $K_{2}$ is the gain value on the strain gauge, that is, the magnification factor (take 500).

Based on the strain value obtained by the above formula, combined with the stress-strain relationship, the axial stress $\sigma(t)$ and shear stress in the drill pipe can be obtained, namely,

$$
\begin{aligned}
\sigma(t) & =E_{0} \varepsilon(t), \\
& =\frac{2 E_{0} U_{x}}{U_{0} K_{1} K_{2}}, \\
\tau(t) & =G_{0} \varepsilon(t), \\
& =\frac{2 G_{0} U_{x}}{U_{0} K_{1} K_{2}},
\end{aligned}
$$

where $G_{0}$ is the shear modulus of the drill pipe.

According to the stress wave propagation law and the one-dimensional stress theory, the calculation formulas for the internal axial stress $\sigma_{a}(t)$, axial strain $\varepsilon_{a}(t)$, and strain rate $\dot{\varepsilon}$ of the rock specimen during the impact process are as follows [40]:

$$
\begin{aligned}
\sigma_{a}(t) & =\frac{E_{0} A_{0}}{2 A_{s}}\left[\varepsilon_{i}(t)+\varepsilon_{r}(t)+\varepsilon_{\mathrm{t}}(t)\right], \\
\varepsilon_{a}(t) & =\frac{c_{0}}{l_{s}} \int_{0}^{t}\left[\varepsilon_{i}(t)-\varepsilon_{r}(t)-\varepsilon_{t}(t)\right] d_{t}, \\
\dot{\varepsilon} & =\frac{c_{0}}{l_{s}}\left[\varepsilon_{i}(t)-\varepsilon_{r}(t)-\varepsilon_{\mathrm{t}}(t)\right] .
\end{aligned}
$$

According to the assumption of stress homogenization $[41,42]$, assuming that the strains at both ends of the sample are equal, that is, $\sigma_{i}(t)+\sigma_{r}(t)=\sigma_{\mathrm{t}}(t)$, then equations (5)-(7) can be transformed into

$$
\begin{aligned}
\sigma_{a}(t) & =\frac{E_{0} A_{0}}{A_{s}}\left[\sigma_{i}(t)+\sigma_{r}(t)\right], \\
\varepsilon_{a}(t) & =\frac{c_{0}}{l_{s}} \int_{0}^{t} \varepsilon_{r}(t) d_{t}, \\
\dot{\varepsilon} & =\frac{c_{0}}{l_{s}} \varepsilon_{r}(t),
\end{aligned}
$$

where $A_{0}$ is the cross-sectional area of the drill pipe, $A_{s}$ is the cross-sectional area of the rock sample, $\varepsilon_{i}(t)$ is the incident wave strain, $\varepsilon_{r}(t)$ is the reflected wave strain, and $\varepsilon_{\mathrm{t}}(t)$ is the transmitted wave strain.

The formula for calculating incident wave energy $E_{\mathrm{i}}$ and reflected wave energy $E_{\mathrm{r}}$ in the drill pipe is $[42,43]$

$$
\left\{\begin{array}{l}
E_{i}=\frac{A c_{0}}{E_{0}} \int_{0}^{t_{p}} \sigma_{i}^{2} \mathrm{~d} t, \\
E_{r}=\frac{A c_{0}}{E_{0}} \int_{0}^{t_{p}} \sigma_{r}^{2} \mathrm{~d} t,
\end{array}\right.
$$


where $t_{p}$ is the duration of the stress wave, which is determined by the experiment.

\section{Test Process and Analysis}

3.1. Rock Sample Preparation. In this test, the rock sample was taken from the site of an underground highway tunnel in Chongqing. The buried depth of the tunnel is about $15 \mathrm{~m}$, the tunnel face is $25 \mathrm{~m}$ wide, and the height is $10 \mathrm{~m}$. The project requires drilling and blasting activities in and around the tunnel. Therefore, the surrounding rock of the tunnel will be subjected to impact loads in different directions. The tunnel site and blasting layout site are shown in Figure 5.

The rock samples in this test are taken from the excavation site of the underground tunnel. The rock samples were cut and then transported to the laboratory. Preliminary analysis shows that the rock samples are typical granite with fine grain size, solid texture, and massive structure. A coring machine takes out the core with good integrity and homogeneity, and then, the core is cut by a rock cutter. According to the size of the rotating rock bin in the test platform and the test recommendations of the International Society for Rock Mechanics, the rocks were processed into cylindrical samples with a diameter of $50 \mathrm{~mm}$ and a height of $100 \mathrm{~mm}$, and the samples were ground to make the surface unevenness less than $0.02 \mathrm{~mm}$. The physical map of the sample is shown in Figure 6. The density, uniaxial compressive strength, elastic modulus, longitudinal wave velocity, and Poisson's ratio of the granite samples are obtained by physical and mechanical tests in the laboratory. The statistical results are shown in Table 1.

\subsection{Relationship between Air Pressure, Impact Velocity, and} Stress. In the impact simulation test, the kinetic energy required for the drill rod to impact the rock sample is obtained after the impact rod impacts, and the impact rod end velocity is determined by the air pressure value of the cylinder of the launch system. Therefore, before the start of the test, it is necessary to calibrate the quantitative relationship between the end velocity of the impact rod and the air pressure value of the cylinder. The specific operation method is to adjust the air pressure value of the cylinder so that the impact rod can obtain an initial speed to rush out of the pipe at a certain launch pressure. At the same time, a microsecond timer (see Figure 3(c)) is used to measure the time for the impact rod to pass a fixed distance. In this way, only a simple conversion relationship is needed to obtain the initial velocity of the striker. In the first test, the air pressure value of the cylinder is set to $2 \mathrm{psi}$, increasing by $1 \mathrm{psi}$ each time until the air pressure value is 20 psi. Perform 3 tests under each pressure value, and take the average of the 3 test results and record. By testing the end velocity of the impact rod under different air pressures, draw a scatter diagram of the cylinder air pressure $P$ (psi) and the impact end velocity $V_{0}(\mathrm{~m} / \mathrm{s})$ of the impact rod, as shown in Figure 7 . The fitting formula is

$$
\begin{aligned}
V_{0} & =0.39062 P+5.98364, \\
R^{2} & =0.99 .
\end{aligned}
$$

It can be seen from the figure that the air pressure impact end velocity of the cylinder is very correlated, and the impact end velocity can be calibrated by adjusting the air pressure. In the following text, different impact end velocities can be used for analysis. The oscilloscope displays different voltages under different working conditions, as shown in Figure 8. Figure $8(\mathrm{a})$ is the output image of the oscilloscope when the impact speed is $7.2 \mathrm{~m} / \mathrm{s}$ and the rotation speed is $225 \mathrm{rpm}$. Figure $8(\mathrm{~b})$ is the output image of the oscilloscope when the impact speed is $11.2 \mathrm{~m} / \mathrm{s}$ and the rotation speed is $66 \mathrm{rpm}$. In the figure, channel 1 is the voltage change caused by the shear strain gauge, channel 2 is the voltage change caused by the tension and compression strain, and channel 3 is the sound level monitoring during the impact. By adjusting the air pressure value, the impact velocity is $7.2,9.4,11.2,13.6$, and $16.8 \mathrm{~m} / \mathrm{s}$. Then, according to the output voltage value of the oscilloscope, using formulas (2) and (4) to convert, you can obtain the tensile and compressive stress wave waveforms at different impact speeds, as shown in Figure 9.

The waveform of the stress wave depends on the shape and length of the impact rod. In this experiment, the impact rod is an equal-diameter cylinder, so the incident stress wave and the reflected stress wave in the tension and compression stress wave are both approximately rectangular. This is consistent with the previous research on the waveform. It can be seen from Figure 9 that, as the impact velocity increases, the amplitude of the incident wave and the reflected wave gradually increase. According to multiple test results, a fitting is performed between the incident wave amplitude and the reflected wave amplitude and the impact velocity, and the result is shown in Figure 10. The analysis indicates that the incident stress wave has a strong correlation with the impact velocity, while the reflected stress wave is related to the rock wave impedance, the degree of closure of internal fissures, and the energy absorption of the rock, so the degree of correlation with the impact velocity is slightly lower than that of the incident wave. The impact speed can be used as a reference for the amplitude of tension and compression stress waves.

The shear force on the drill pipe is obtained at the moment of impact contact between the drill pipe and the high-speed rotating rock sample. The rotation speed of the rock sample is fixed at $66 \mathrm{rpm}$ by adjusting the rotating system, and the impact test is carried out at 5 different impact speeds. According to the output voltage of the oscilloscope and combining (3) and (5), the calculated scatter plot is shown in Figure 11. It can be seen from the figure that when the rotation speed is constant, the amplitude of the shear stress in the drill pipe increases with the increase of the impact speed, which is positively correlated, but the increase rate gradually slows down. The shape of the shear stress wave is slightly different from the tensile-compression stress wave. This is because the reason and method of the formation of the shear stress wave are different from the tensile-compression stress wave. Because the drill pipe and the rock 

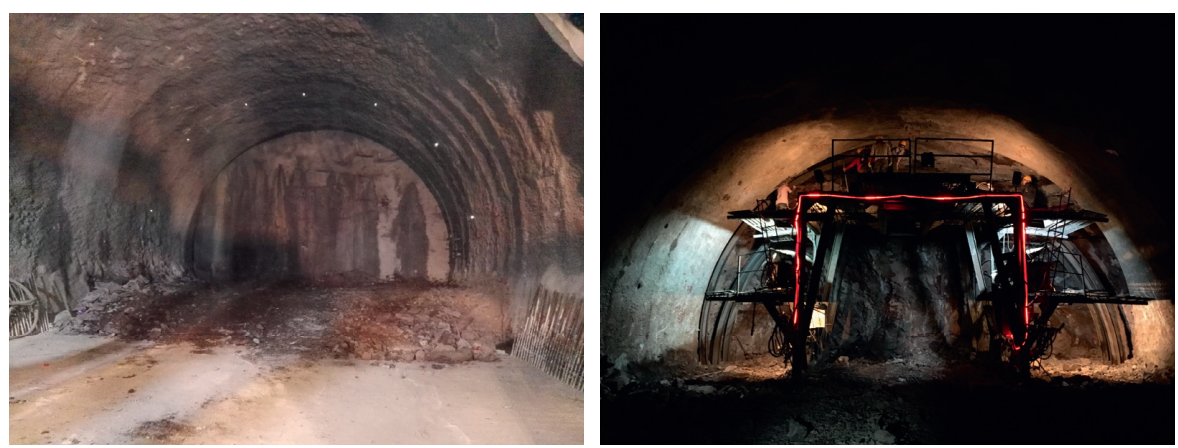

(a)
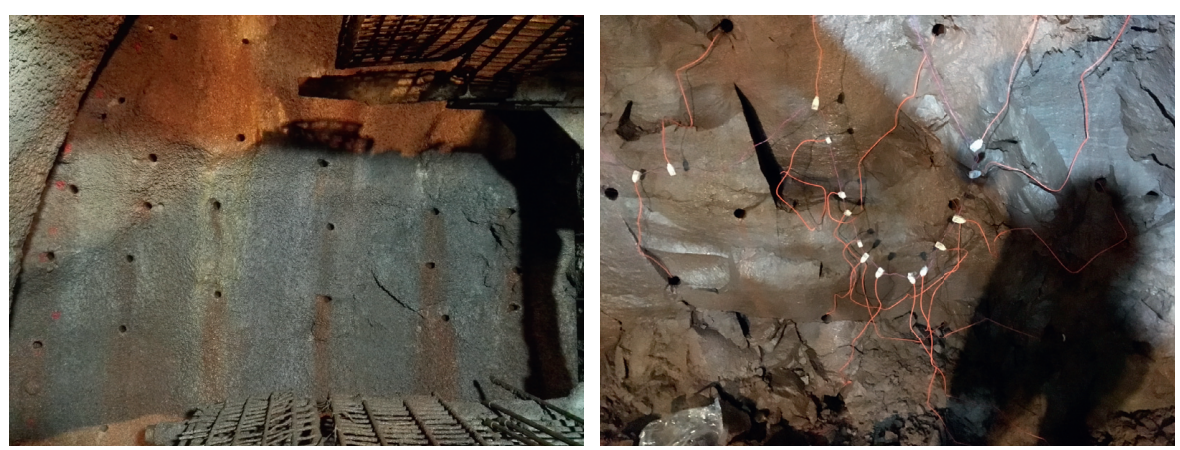

(b)

Figure 5: Tunnel excavation. (a) Tunnel face. (b) Blasting layout site.

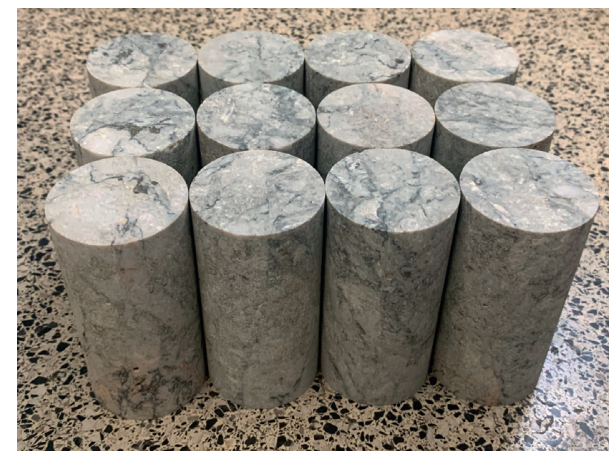

FIgure 6: Part of the rock sample.

sample have a shorter contact time, the shear stress wave duration (wavelength) is less than the tension and compression stress wave.

To further determine the relationship and law of the shear stress, impact velocity, and rotation velocity, the effect of impact velocity on shear stress amplitude under various speeds was examined. The test results are shown in Figure 12. As shown in the figure, the shear stress increases with the increase in the impact speed at the same rotation speed. At the same impact speed, the shear stress also increases with the increase in the rotational speed, and the increasing trend of the shear stress is more obvious with the increase in the impact speed. When the impact speed is low, taking 7.2 and $9.4 \mathrm{~m} / \mathrm{s}$ as examples, the shear stress will increase with the increase in the rotational speed before the rotational speed reaches $120 \mathrm{rpm}$. However, when the speed exceeds $120 \mathrm{rpm}$, the shear stress almost does not increase with the increase in the rotational speed. When the impact speed is 11.2 and $13.6 \mathrm{~m} / \mathrm{s}$, the shear stress exhibits an obvious linear growth trend before the rotation speed reaches $120 \mathrm{rpm}$. When the rotation speed continues to increase, the increase in the shear stress is significantly reduced and almost stops when the speed reaches $225 \mathrm{rpm}$. When the impact velocity is $16.8 \mathrm{~m} / \mathrm{s}$, with the increase in the rotation speed, the shear stress always has a significant increasing trend, and the increase rate is only slightly reduced in the final stage. The above analysis shows that, under a fixed impact velocity, the shear stress has a corresponding upper limit of the rotation speed. When the rotation speed is lower than this upper limit, the shear stress will increase with the increase in the rotation speed and present an approximately linear relationship in the initial stage. Then, the growth rate will gradually decrease. When the rotation speed continues to increase until it is higher than this upper limit, the shear stress will no longer increase with the increase in the rotation speed.

\subsection{Impact Times Required for Specimen Failure under Cyclic} Loading. The previous test results indicate that the impact velocity has a strong correlation with tensile and compressive stresses and shear stresses. When the rock is subjected to pressure that exceeds its resistance strength or the damage reaches a certain value under the action of cyclic loading, failure will occur. In this part, the cyclic impact failure law of the specimen under different impact speeds and rotation speeds is studied. The rotating speed is set at 0 , 
TABle 1: Physical and mechanical parameters of the rock sample.

\begin{tabular}{lccccc}
\hline Rock types & Density $\left(\mathrm{kg} / \mathrm{m}^{3}\right)$ & Compressive strength $(\mathrm{MPa})$ & Elastic modulus $(\mathrm{GPa})$ & P-wave velocity $(\mathrm{m} / \mathrm{s})$ & Poisson's ratio \\
\hline Granite & 2560 & 208 & 18.39 & 4400 & 0.09
\end{tabular}

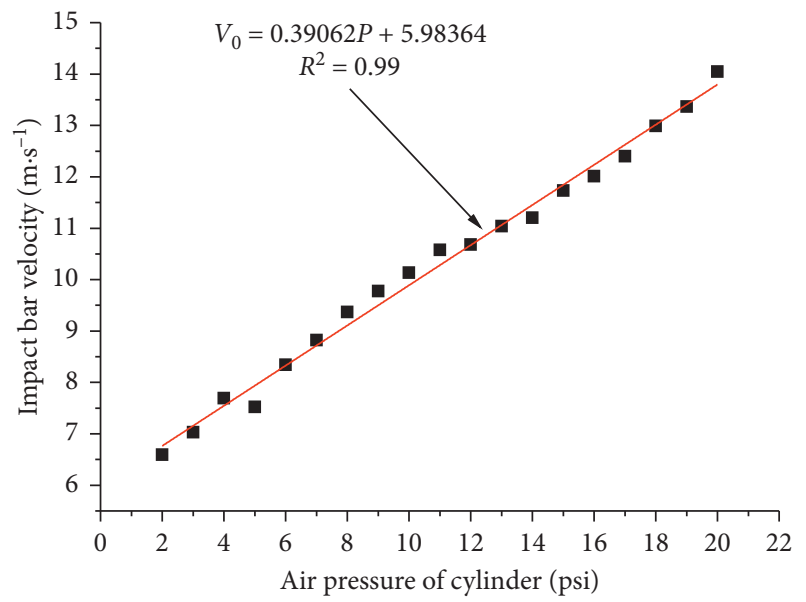

FIgURE 7: Relationship between cylinder air pressure and impact end velocity.

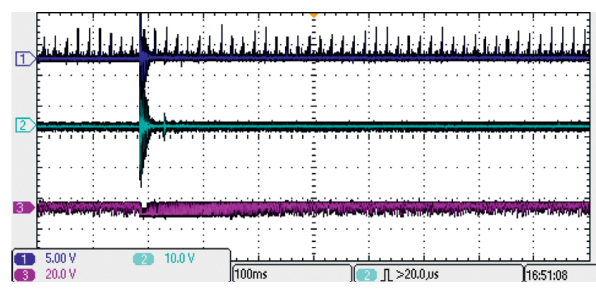

(a)

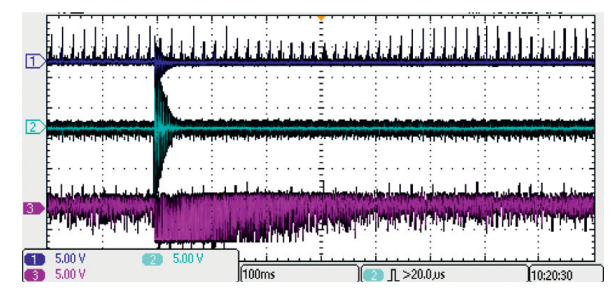

(b)

FIGURE 8: Schematic diagram of the oscilloscope interface under different working conditions. (a) Impact speed $7.2 \mathrm{~m} / \mathrm{s}$; rotation speed $225 \mathrm{rpm}$. (b) Impact speed $11.2 \mathrm{~m} / \mathrm{s}$; rotation speed $66 \mathrm{rpm}$.

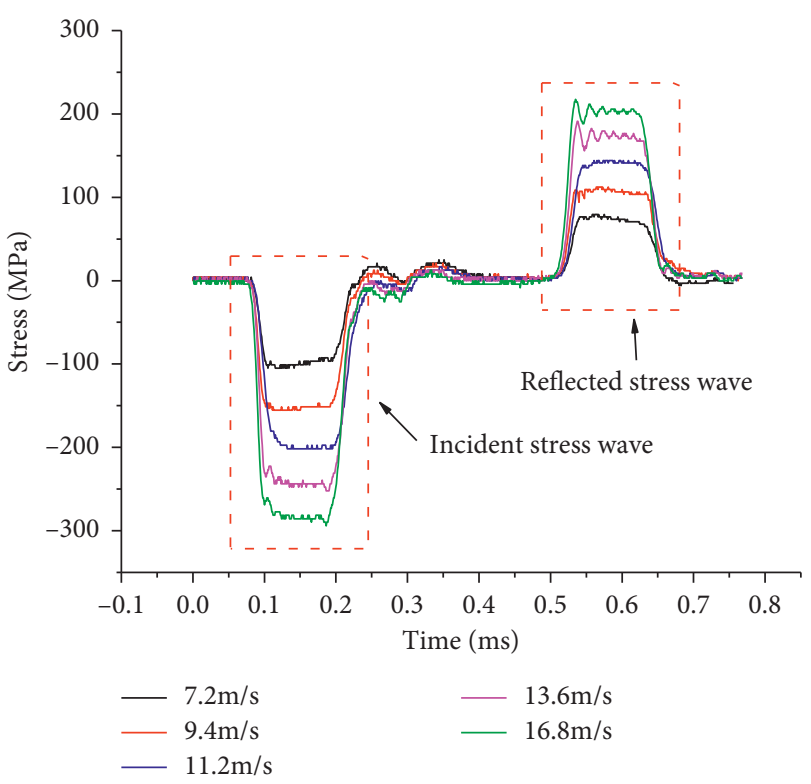

Figure 9: Tension and compression stress wave waveform.

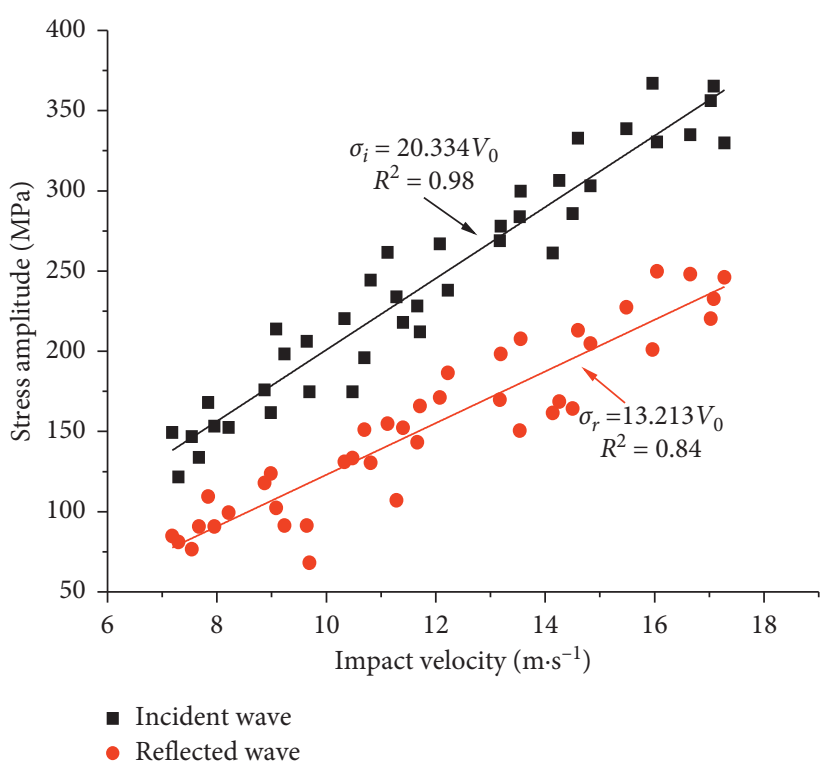

FIGURE 10: Relationship between tensile and compression stress wave amplitude and impact velocity. 


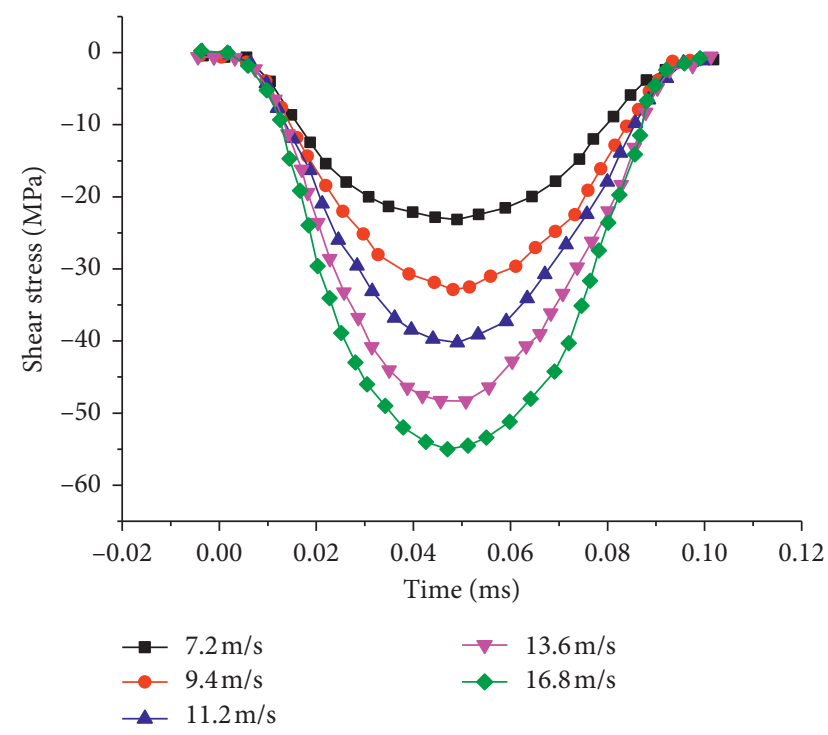

FIGURE 11: Shear stress waveform.

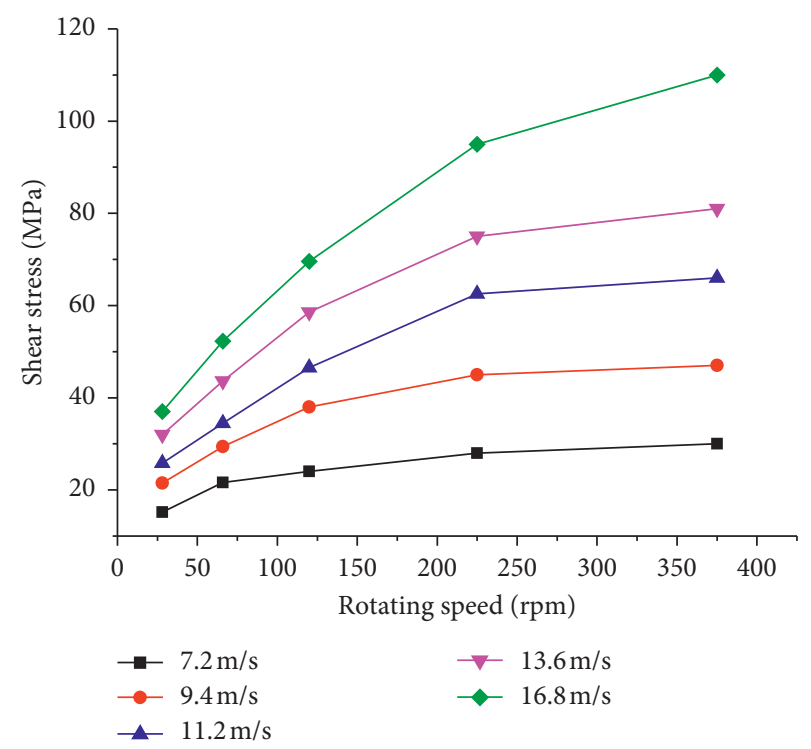

Figure 12: Shear stress under different conditions.

$28,66,120,225$, and $375 \mathrm{rpm}$, and the samples are subjected to cyclic impact with five different impact speeds until macroscopic failure occurs. Table 2 lists the number of impacts when the specimen is damaged at different speeds and draws a scatter chart, as shown in Figure 13. The figure shows that, at the same impact speed, a great rotation speed corresponds to fewer impacts required for failure, indicating that the rock is more prone to fatigue failure under the combined action of impact load and shear.

3.4. Stress-Strain Curve of the Sample under Cyclic Load. The stress-strain curve is an important basis for judging rock failure under cyclic loading. Figure 12(a) shows the stressstrain curve of a typical rock when macroscopic failure has not occurred. The total sample is in an elastic and
TABLE 2: Impact times under different rotation speeds and impact speeds.

\begin{tabular}{lccccc}
\hline \multirow{2}{*}{ Rotation speed (rpm) } & \multicolumn{5}{c}{ Impact speed (m/s) } \\
& 7.2 & 9.4 & 11.2 & 13.6 & 16.8 \\
\hline 0 & 45 & 37 & 22 & 12 & 6 \\
28 & 43 & 36 & 19 & 11 & 6 \\
66 & 39 & 33 & 17 & 10 & 5 \\
120 & 35 & 26 & 14 & 6 & 4 \\
255 & 30 & 24 & 12 & 5 & 2 \\
375 & 27 & 23 & 11 & 4 & 2 \\
\hline
\end{tabular}

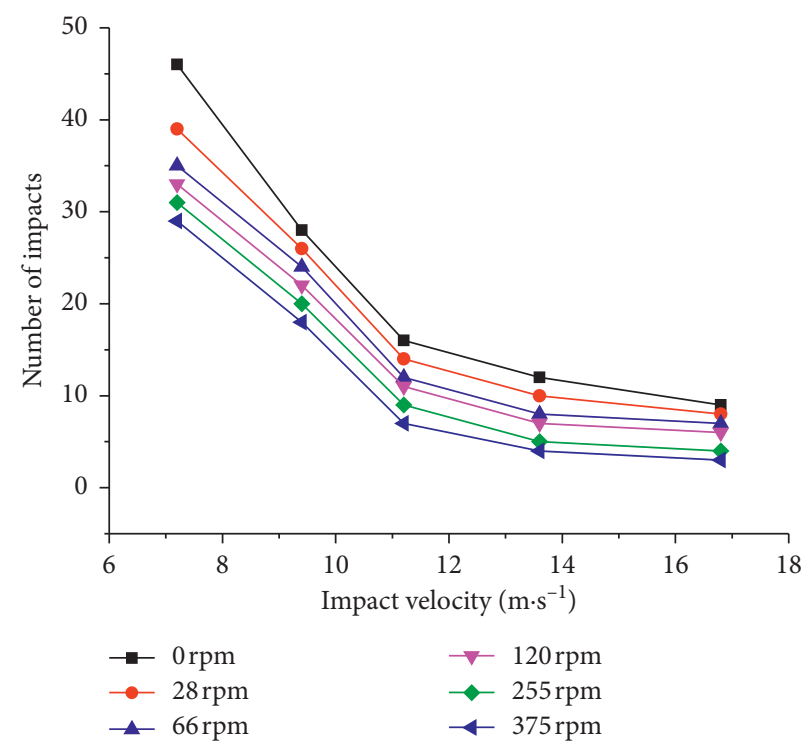

FIgURE 13: Relationship between impact times and impact speed at different speeds.

elastoplastic state during the entire process. The stress-strain curve can be roughly divided into four stages according to the development process: compaction phase $(\mathrm{AB})$, elastic phase (BC), crack development phase (CD), and unloading phase (DE). The compaction phase is the process of closing the internal fissures of the rock. The elastic stage is the elastic deformation (recoverable) of the rock sample after compaction. In these two processes, the rock is not damaged, either macroscopically or microscopically. The crack development stage is the stable development stage of the internal cracks in the rock. At this time, the rock does not undergo macroscopic damage, and only part of the damage is accumulated in the microscopic view. The unloading stage is a process in which the strain of the rock gradually decreases as the stress decreases. When the specimen undergoes macroscopic failure, the curve in the unloading phase in the stress-strain curve changes most significantly. Even if the stress no longer increases, the stress still increases, and the rock is in a state of plastic yield.

The following is an analysis of the stress-strain curve of the sample under the same impact speed and different rotation speeds. Under the condition of the impact velocity of $13.6 \mathrm{~m} / \mathrm{s}$, the stress-strain curve of the specimen at different rotation speeds is drawn, as shown in Figure 14. The figure 

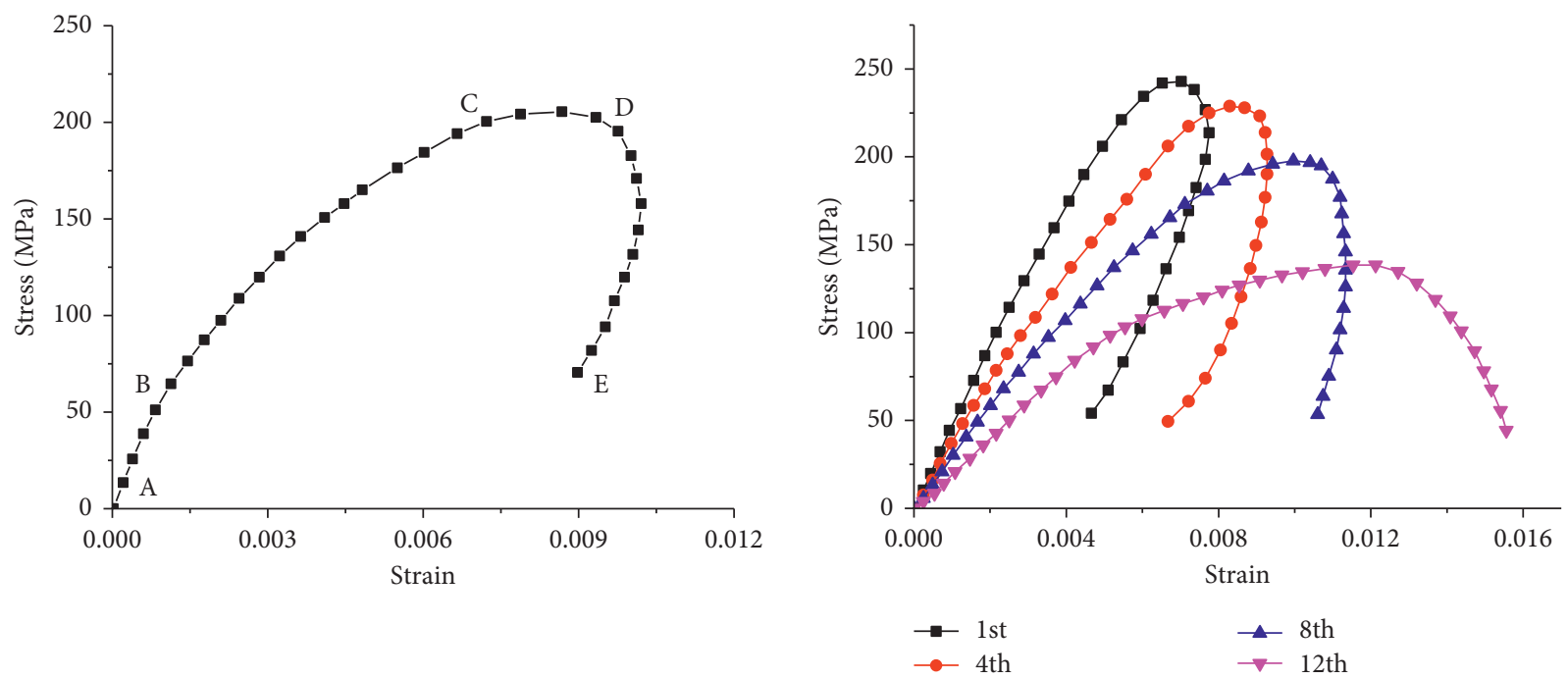

(a)
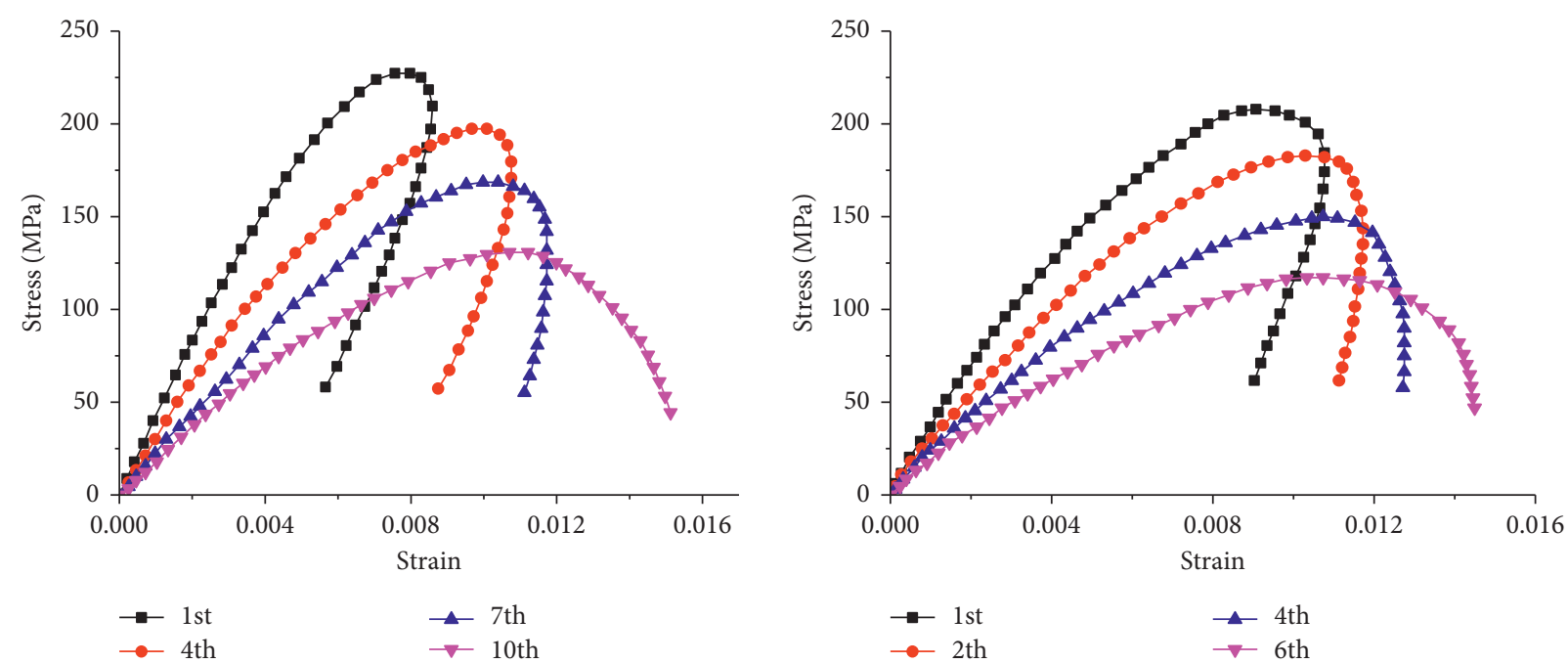

(c)

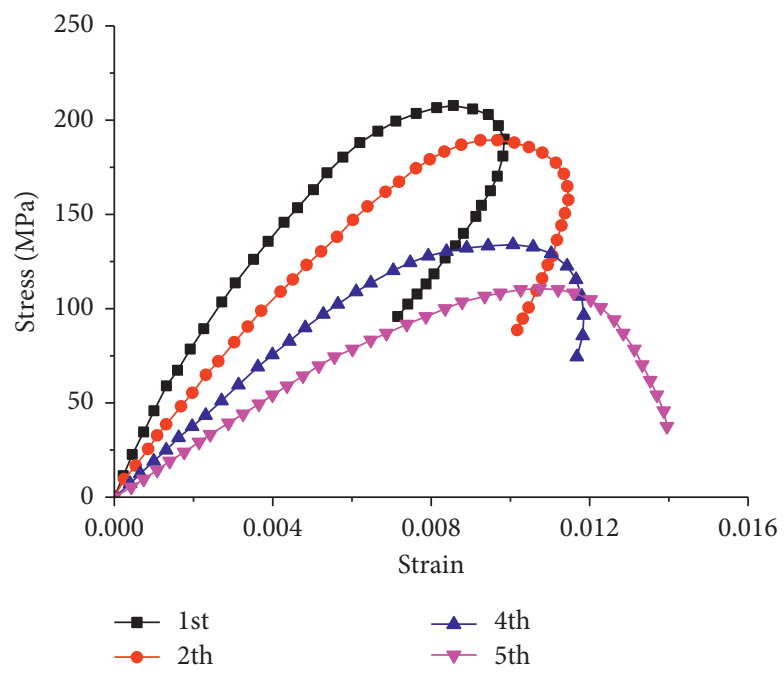

(e)

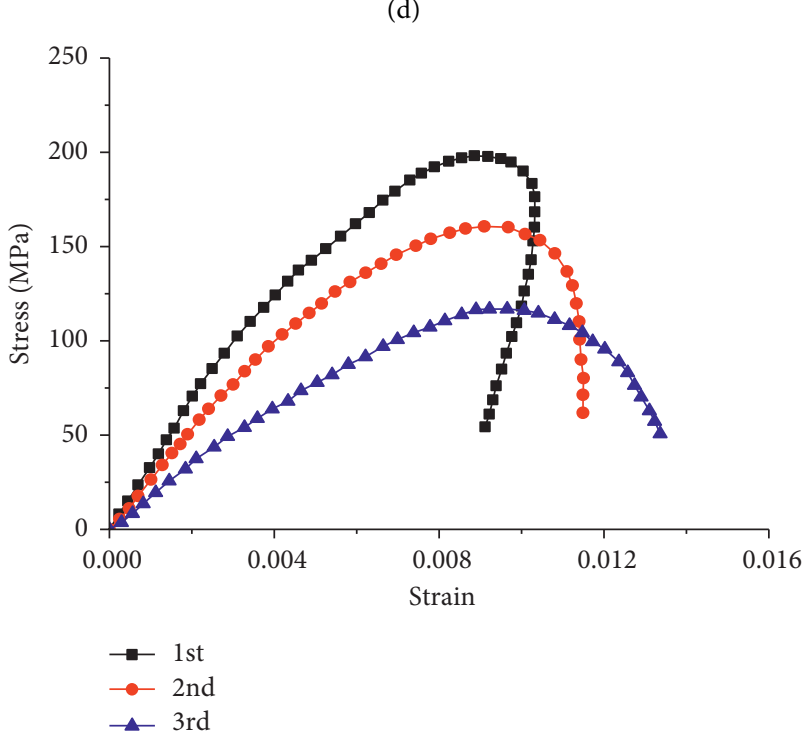

(f)

Figure 14: Stress-strain curve with the impact velocity of $13.6 \mathrm{~m} / \mathrm{s}$. (a) Typical stress-strain curve. (b) Rotation speed is $0 \mathrm{rpm}$. (c) Rotation speed is $66 \mathrm{rpm}$. (d) Rotation speed is $120 \mathrm{rpm}$. (e) Rotation speed is $255 \mathrm{rpm}$. (f) Rotation speed is $375 \mathrm{rpm}$. 
shows that when the impact velocity is the same, the shape and development process of the stress-strain curve of the specimen at different rotational speeds are consistent with that of the static sample, indicating that the existence of shear stress does not affect the overall change trend of the axial compression stress-strain curve of the specimen. Figure 12 shows that, under the premise of keeping the impact velocity constant, the number of failures of the rock sample gradually decreases as the rotation speed increases. At the same time, under the same number of impacts, the slope of the elastic phase (BC phase) of the stress-strain curve gradually decreases with the increase in speed, which means that when the rock reaches the same strain, the required stress value is smaller. A comparison of the stressstrain curve under the first impact at different rotation speeds shows that the corresponding stress at the peak of the curve gradually decreases with the increase in the rotation speed, which indicates that the increase in the rotation speed will reduce the rock sample to the deformation failure stage (CD stage) stress value, that is, the failure stage of the internal crack propagation of the rock sample under lower stress.

3.5. Energy Dissipation Law under Different Conditions. It can be seen from the previous analysis that increasing shear stress under cyclic impact load can accelerate rock failure. The disturbance caused by stress and strain propagates in the solid at a certain speed in the form of a wave, which is called a stress wave. The energy absorption of rock failure is mainly used for the kinetic energy required for the closure, development, penetration, and failure of internal fissures. The more the energy absorption, the faster the development of rock failure, so the energy dissipation rate can be used as the basis for the degree of rock damage.

The stress wave energy can be calculated by (11). It can be seen from the formula that the stress wave energy is related to the drill pipe cross-sectional area, elastic modulus (shear modulus), wave velocity, stress value, and time. Among them, the cross-sectional area, elastic modulus, and wave velocity of the drill pipe are only related to the material of the drill pipe. The stress wave stress value and time can be obtained from the waveform diagram. According to the waveform data obtained by the oscilloscope, the stress wave energy can be calculated by combining (11).

To discuss the energy dissipation of stress waves and the law of rock absorption under cyclic loading, the fracture specific energy $\delta$ is defined as the cumulative energy absorbed per unit volume of the rock specimen in the process of cyclic impact failure. The calculation formula is as follows:

$$
\begin{aligned}
\delta & =\sum_{k=1}^{n} E_{V k}, \\
& =\sum_{k=1}^{n}\left(\frac{E_{\mathrm{ik}}-E_{\mathrm{rk}}}{V_{s}}\right),
\end{aligned}
$$

where $\delta$ is the specific energy of crushing, $E_{V k}$ is the absorbed energy per unit volume generated by the $k$ th impact of the sample, $V_{s}$ is the volume of the rock sample, $n$ is the number of the cyclic effects, $E_{i k}$ is the incident wave energy of the $k$ th impact, and $E_{r k}$ is the energy of the $k$ th impact reflected wave.

From the test results and equations (11) and (13), the required $\delta$ in the rock breaking process can be obtained. The calculation result is shown in Figure 15.

The figure shows that when no rotating load is applied to the rock sample, the impact velocity with the smallest crushing specific energy is $11.2 \mathrm{~m} / \mathrm{s}$, which can also be considered as the optimal damage impact velocity for this kind of rock. With the increase in speed, the crushing ratio required for the destruction of the sample gradually decreases, but the decrease is related to the speed. When the rotation speed is in the range of $0-120 \mathrm{rpm}$, the specific energy curves of unit volume under different impact speeds show a trend of first decreasing and then increasing. The optimal failure impact speed is $9.4 \mathrm{~m} / \mathrm{s}$ when the rotation speed is $66 \mathrm{rpm}$, and the optimal failure impact speed of other rotation speeds $(0,32$, and $120 \mathrm{rpm})$ is $11.2 \mathrm{~m} / \mathrm{s}$. For a certain kind of rock, the crushing specific energy is different at different impact speeds. For the tested rock in this experiment, when there is no shear stress (that is, when the rotation speed is $0 \mathrm{rpm}$ ), the optimal damage impact velocity is $11.2 \mathrm{~m} / \mathrm{s}$. It can be seen from the figure that when the rotation speed is increased to $28 \mathrm{rpm}$, although $11.2 \mathrm{~m} / \mathrm{s}$ is still the optimal damage impact velocity, compared with other impact velocities, the gap in crushing specific energy is significantly reduced. When the rotation speed is $66 \mathrm{rpm}$, the optimal impact speed becomes $9.4 \mathrm{~m} / \mathrm{s}$. The reason is analyzed because the shear stress generated by $0 \mathrm{rpm}$ and $28 \mathrm{rpm}$ is small, and the impact on the impact damage is also small. When the speed increased to $66 \mathrm{rpm}$, the influence of shear stress began to increase, and the optimal impact speed was effectively reduced. It can be considered that, for the type of rock used in this experiment, the shear stress when the rotation speed reaches $66 \mathrm{rpm}$ is an effective intervention point.

With the continuous increase in the rotation speed, the optimal impact velocity also gradually increases. When the speed reaches $375 \mathrm{rpm}$, the crushing specific energy of $16.8 \mathrm{~m} / \mathrm{s}$ impact speed is significantly lower than that of other impact speeds, and its value is only $30 \%$ of the crushing specific energy when the impact speed is $7.2 \mathrm{~m} / \mathrm{s}$. From the above analysis, it is not difficult to find that when there is no shear stress (rotation speed is $0 \mathrm{rpm}$ ), the rock sample used in this test has the lowest impact speed of $11.2 \mathrm{~m} / \mathrm{s}$. When the rotation speed gradually increased to $66 \mathrm{rpm}$, the shear stress effectively reduced the optimal impact velocity, making the optimal impact velocity $9.4 \mathrm{~m} / \mathrm{s}$. As the shear stress continues to increase, the optimal damage impact velocity also increases. In summary, as the shear stress increases, the optimal damage impact velocity has experienced the first drop, and in the process of rising, there is an inflection point. The impact velocity of $7.2 \mathrm{~m} / \mathrm{s}$ does not become the optimal impact velocity at different rotation speeds because a large 


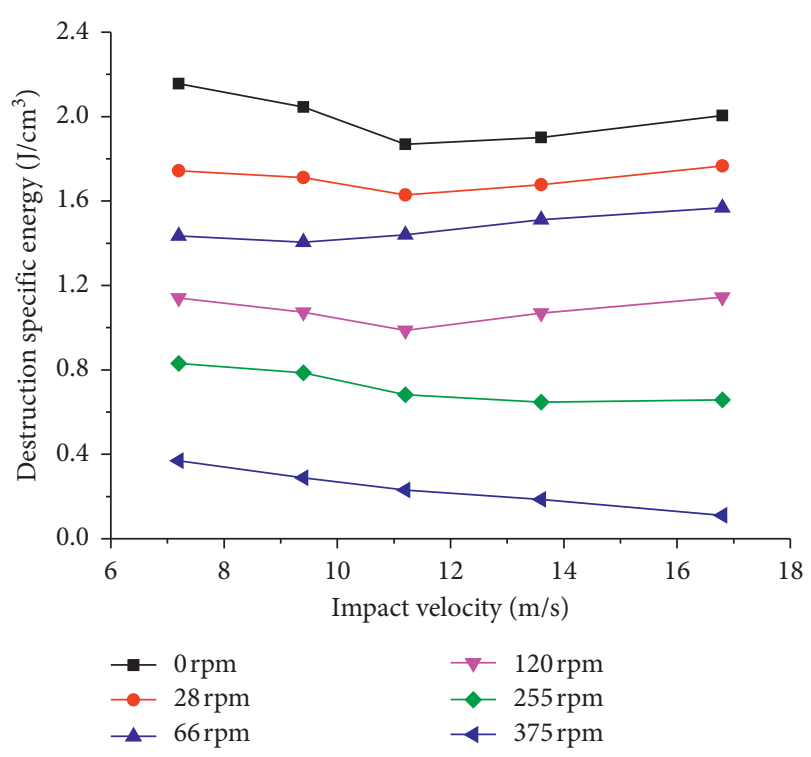

Figure 15: Specific crushing energy under different working conditions.

part of the stress wave energy is used in the compression and elastic stages of rock deformation at low speed. In contrast, the energy used for macrofailure processes, such as crack development of rock failure, is relatively small. The above analysis process indicates that the reasonable selection of impact speed and rotation speed will have a great influence on the rock-breaking efficiency for a specific rock type.

\section{Discussion}

Explosive stress wave reflection tensile theory states that when the rock is broken, the tensile stress inside the rock is greater than its tensile strength due to the effect of the tensile wave after the stress wave is reflected on the free surface. Under the action of cyclic loading, the internal cracks of the rock continue to develop, which also reduces the tensile strength of the rock, causing the rock to be destroyed even under the action of a lower stress wave. The surrounding rock of the tunnel is in a complex geological environment. Under the action of in situ stress, the surrounding rock of the tunnel is subjected not only to multidirectional static loads and blasting impact loads but also to shear loads, such as the superposition of stress waves in different directions, shield construction, and other rotation drilling works. Rock is a material whose shear strength is less than its compressive strength. When subjected to shear, it will inevitably lead to a lower threshold for failure.

When the impact velocity remains the same, the number of impacts required for rock failure decreases with the increase in the rotation speed, indicating that the increase in the rotation speed and the shear force promotes the failure of the rock. Fissures are more likely to be torn; they are easier to penetrate compared with a simple compression process. We can easily see that the increase in rotation speed does not lead to an obvious change of the curve, which indicates that the shear force does not directly participate in the change in the axial deformation of rock. Independent analysis can be performed in the axial compression and calculation. From the perspective of energy analysis, when the shear stress increases, the crushing ratio energy required for rock failure gradually decreases. The energy needed for rock failure is a fixed value; thus, we can determine that the work performed by the shear stress gradually increases during the failure process, but this part of the energy is not reflected in the axial compression deformation. Therefore, in actual tunnel engineering, the stress-strain analysis under the simple impact of the surrounding rock may lead to inaccurate predictions of damage, resulting in accidents. Therefore, when the surrounding rock of the tunnel is subjected to superimposed effects of blasting impacts in different directions or rotationimpact load, construction personnel must pay special attention to the corresponding support and reinforcement measures of the surrounding rock.

\section{Conclusions}

(1) In this paper, the dynamic impact simulation test bench developed by the authors is used to study the law of rock damage under rotating cyclic impact load. The research results show that compared with the traditional cyclic impact test, the appearance of shear force will accelerate the process of rock failure and reduce the number of impacts required for rock failure. A great impact speed corresponds to a great change brought about by the increase in rotation speed. When the impact speed is $7.2 \mathrm{~m} / \mathrm{s}$, the number of impacts at the maximum speed is $60 \%$ of the static state; when the impact speed is $16.8 \mathrm{~m} / \mathrm{s}$, this value is only $33.3 \%$.

(2) When the rotation speed is constant, the increase in the impact speed will lead to an increase in the shear force, but this increase will gradually decrease. When the impact velocity is constant, the increase in the rotation speed of the rock sample will lead to an increase in the shear stress, but an upper limit exists. When this upper limit is exceeded, the shear stress no longer increases with the increase in the rotation speed. This situation can provide an idea for the failure process of rock drilling, reduce energy loss, and improve drilling efficiency.

(3) Under different shear stress, the stress-strain curve of rock under impact has no obvious change, but the slope of the elastic stage in the curve decreases, that is, the stress value required for strain in rock decreases. This finding shows that the crack development and penetration speed are faster under shear stress, which is also the main reason the rock is more easily damaged under shear stress. In tunnel engineering, judging safety based on only the axial deformation of the surrounding rock mass or the stress-strain curve is risky. When the surrounding rock is subjected to impact loads from different directions or rotating impact damage, special attention should be paid to the safety situation, and 
timely support and reinforcement measures should be taken.

(4) An analysis of the specific energy of rock fragmentation under different working conditions indicates that the increase in shear stress will cause particular fragmentation energy to decrease. The rotating sample provides the shear stress wave in this test. Therefore, for the time being, only the energy of the tensile and compressive stress wave is calculated and analyzed. Future research will focus on the energy dissipation of the shear stress wave.

(5) The drill bit used in this article is a three-wing PDC drill bit. There are many different types and sizes of drill bits in actual engineering. The influence of different drill bits on the mechanism of failure is a direction that needs to be studied in the future. At the same time, the shear stresses in this paper are all instantaneous stresses, and whether the failure mechanism of rock is different when the shear stress is constant is also the content that needs to be studied in the follow-up work.

\section{Data Availability}

The data included in this study are available from the corresponding author upon request.

\section{Conflicts of Interest}

The authors declare that they have no conflicts of interest.

\section{Acknowledgments}

The authors would like to thank the National Natural Science Foundation of China (no. 51574015), National Key R\&D Program of China (2018YFC0808701), and China Postdoctoral Science Foundation (2020M673525) for their sponsorship.

\section{References}

[1] Q. Sun, D. Dias, L. R. E. Sousa, and W. Liu, "Soft soil layertunnel interaction under seismic loading," Tunnelling and Underground Space Technology, vol. 98, Article ID 103329, 2020.

[2] W. Yu, W. Wang, X. Chen, and S. Du, "Field investigations of high stress soft surrounding rocks and deformation control," Journal of Rock Mechanics and Geotechnical Engineering, vol. 7, no. 4, pp. 421-433, 2015.

[3] S. Wang, C. Li, Z. Liu, and J. Fang, "Optimization of construction scheme and supporting technology for HJS soft rock tunnel," International Journal of Mining Science and Technology, vol. 24, no. 6, pp. 847-852, 2014.

[4] P. X. Li, X. T. Feng, G. L. Feng, Y. X. Xiao, and B. R. Chen, "Rockburst and microseismic characteristics around lithological interfaces under different excavation directions in deep tunnels,” Engineering Geology, vol. 260, pp. 105-209, 2019.

[5] M. Ramulu, A. K. Chakraborty, and T. G. Sitharam, "Damage assessment of basaltic rock mass due to repeated blasting in a railway tunnelling project-a case study," Tunnelling and
Underground Space Technology, vol. 24, no. 2, pp. 208-221, 2009.

[6] K. Dey and V. M. S. R. Murthyd, "Prediction of blast-induced overbreak from uncontrolled burn-cut blasting in tunnels driven through medium rock class," Tunnelling and Underground Space Technology incorporating Trenchless Technology Research, vol. 28, pp. 49-56, 2012.

[7] J. H. Shin, H. G. Moon, and S. E. Chae, "Effect of blast-induced vibration on existing tunnels in soft rocks," Tunnelling and Underground Space Technology Incorporating Trenchless Technology Research, vol. 26, no. 1, pp. 51-61, 2011.

[8] A. Ansell, "In situ testing of young shotcrete subjected to vibrations from blasting," Tunnelling and Underground Space Technology Incorporating Trenchless Technology Research, vol. 19, no. 6, pp. 587-596, 2004.

[9] J. Zhao and J. G. Cai, "Transmission of elastic P-waves across single fractures with a nonlinear normal deformational behavior," Rock Mechanics and Rock Engineering, vol. 41, no. 1, pp. 3-22, 2001.

[10] C. O. Aksoy, K. Ogul, I. Topal, S. C. Ozer, V. Ozacar, and E. Posluk, "Numerical modeling of non-deformable support in swelling and squeezing rock," International Journal of Rock Mechanics and Mining Sciences, vol. 52, pp. 61-70, 2012.

[11] M. Ramoni and G. Anagnostou, "The interaction between shield, ground and tunnel support in TBM tunnelling through squeezing ground," Rock Mechanics and Rock Engineering, vol. 44, no. 1, pp. 37-61, 2011.

[12] D. P. Do, N. T. Tran, V. T. Mai, D. Hoxha, and M. N. Vu, "Time-dependent reliability analysis of deep tunnel in the viscoelastic burger rock with sequential installation of liners," Rock Mechanics and Rock Engineering, vol. 53, no. 3, pp. 1-27, 2020.

[13] G. Barla, M. Bonini, and M. Semeraro, "Analysis of the behaviour of a yield-control support system in squeezing rock," Tunnelling and Underground Space Technology, vol. 26, no. 1, pp. 146-154, 2011.

[14] E. T. Ağbay and T. Topal, "Evaluation of twin tunnel-induced surface ground deformation by empirical and numerical analyses (NATM part of Eurasia tunnel, turkey)," Computers and Geotechnics, vol. 119, Article ID 103367, 2020.

[15] P. K. Singh, "Blast vibration damage to underground coal mines from adjacent open-pit blasting," International Journal of Rock Mechanics and Mining ences, vol. 39, no. 8, pp. 959-973, 2002.

[16] J. S. Sharma, A. M. Hefny, J. Zhao, and C. W. Chan, "Effect of large excavation on deformation of adjacent MRT tunnels," Tunnelling and Underground Space Technology Incorporating Trenchless Technology Research, vol. 16, no. 2, pp. 93-98, 2001.

[17] N. Li, W. Chen, P. Zhang, and G. Swoboda, "The mechanical properties and a fatigue-damage model for jointed rock masses subjected to dynamic cyclical loading," International Journal of Rock Mechanics and Mining Sciences, vol. 38, no. 7, pp. 1071-1079, 2001.

[18] M. N. Bagde and V. Petro, "Fatigue and dynamic energy behaviour of rock subjected to cyclical loading," International Journal of Rock Mechanics \& Mining Sciences, vol. 46, no. 1, pp. 200-209, 2009.

[19] E. Liu and S. He, "Effects of cyclic dynamic loading on the mechanical properties of intact rock samples under confining pressure conditions," Engineering Geology, vol. 125, no. 27, pp. 82-91, 2012.

[20] J. C. Li and G. W. Ma, "Experimental study of stress wave propagation across a filled rock joint," International Journal of 
Rock Mechanics and Mining Sciences, vol. 46, no. 3, pp. 375-380, 2009.

[21] Y. L. Lu, D. Elsworth, and L. G. Wang, "Microcrack-based coupled damage and flow modeling of fracturing evolution in permeable brittle rocks," Computers and Geotechnics, vol. 49, no. 4, pp. 226-244, 2013.

[22] J. Y. Fang, F. N. Dang, Y. T. Xiao, W. H. Ding, and J. X. Fang, "Quantitative study on the CT test process of siltstone under triaxial compression," Chinese Journal of Rock Mechanics and Engineering, vol. 34, no. 10, pp. 1976-1984, 2015.

[23] J. H. Chen, J. S. Zhang, and X. P. Li, "Model of rock blastinginduced damage considering integrity of rock mass and its application," Chinese Journal of Geotechnical Engineering, vol. 38, no. 5, pp. 857-866, 2016.

[24] L. Zhang, D. Yang, and Z. Chen, "Deformation and failure characteristics of weathered granite under uniaxial compression," AIP Advances, vol. 9, no. 7, pp. 205-222, 2019.

[25] Y. H. Wang, Y. F. Liu, and H. T. Ma, "Changing regularity of rock damage variable and resistivity under loading condition," Safety Science, vol. 50, no. 4, pp. 718-722, 2012.

[26] Z. Y. Li, G. Wu, T. Z. Huang, and Y. Liu, "Variation of energy and criteria for strength failure of shale under traixial cyclic loading," Chinese Journal of Rock Mechanics and Engineering, vol. 37, no. 3, pp. 662-670, 2018.

[27] C. H. Dowding, "Estimating earthquake damage from explosion testing of full-scale tunnels," Advances in Tunnelling Technology and Subsurface Use, vol. 4, no. 3, pp. 113-119, 1984.

[28] C. H. Dowding, "Blast vibration monitoring and control," Mining Science and Technology, vol. 2, no. 4, pp. 308-309, 1985.

[29] J. Zhao, Y. X. Zhou, A. M. Hefny et al., "Rock dynamics research related to cavern development for ammunition storage," Tunnelling and Underground Space Technology, vol. 14, no. 4, pp. 513-526, 1999.

[30] S. G. Chen, J. G. Cai, J. Zhao, and Y. X. Zhou, "Discrete element modelling of an underground explosion in a jointed rock mass," Geotechnical \& Geological Engineering, vol. 18, no. 2, pp. 59-78, 2000.

[31] H. Hao, Y. Wu, G. Ma, and Y. Zhou, "Characteristics of surface ground motions induced by blasts in jointed rock mass," Soil Dynamics and Earthquake Engineering, vol. 21, no. 2, pp. 85-98, 2001.

[32] Y. Zhou and A. Jenssen, "Internal separation distances for underground explosives storage in hard rock," Tunnelling and Underground Space Technology Incorporating Trenchless Technology Research, vol. 24, no. 2, pp. 119-125, 2009.

[33] X. F. Deng, J. B. Zhu, S. G. Chen, Z. Y. Zhao, Y. X. Zhou, and J. Zhao, "Numerical study on tunnel damage subject to blastinduced shock wave in jointed rock masses," Tunnelling and Underground Space Technology, vol. 43, no. 6, pp. 88-100, 2014.

[34] Z. Y. Zhao, S. G. Chen, J. B. Zhu, X. F. Deng, Y. X. Zhou, and J. Zhao, "UDEC-AUTODYN hybrid modeling of a large-scale underground explosion test," Rock Mechanics and Rock Engineering, vol. 48, no. 2, pp. 737-747, 2015.

[35] J. B. Zhu, Y. S. Li, S. Y. Wu, R. Zhang, and L. Ren, "Decoupled explosion in an underground opening and dynamic responses of surrounding rock masses and structures and induced ground motions: a FEM-DEM numerical study," Tunnelling and Underground Space Technology incorporating Trenchless Technology Research, vol. 82, no. 12, pp. 442-454, 2018.

[36] W. C. Cheng, J. C. Ni, A. Arulrajah, and H. W. Huang, "A simple approach for characterising tunnel bore conditions based upon pipe-jacking data," Tunnelling and Underground Space Technology, vol. 71, no. 1, pp. 494-504, 2018.

[37] W. C. Cheng, L. Wang, Z. F. Xue, J. C. Ni, M. M. Rahman, and A. Arulrajah, "Lubrication performance of pipejacking in soft alluvial deposits," Tunnelling and Underground Space Technology, vol. 91, Article ID 102991, 2019.

[38] W. C. Cheng, G. Li, N. Liu, J. Xu, and S. Horpibulsuk, "Recent massive incidents for subway construction in soft alluvial deposits of Taiwan: a review," Tunnelling and Underground Space Technology, vol. 96, Article ID 103178, 2020.

[39] H. Kolsky, "An investigation of the mechanical properties of materials at very high rates of loading," Proceedings of the Physical Society B, vol. 62, no. 11, p. 676, 1949.

[40] Q. Ping, X. Luo, Q. Y. Ma, and P. Yuan, "Broken energy dissipation characteristics of sandstone specimens under impact loads," Chinese Journal of Rock Mechanics and Engineering, vol. 34, no. 9, pp. 4197-4203, 2015.

[41] L. Song and S. S. Hu, "Two-wave and three-wave method in SHPB data processing," Explosion and Shock Waves, vol. 25, no. 4, pp. 368-373, 2005.

[42] C. J. Xia, H. P. Xie, Y. Ju, and H. W. Zhou, "Experimental study of energy dissipation of porous rock under inpact loading," Engineering Mechanics, vol. 23, no. 9, pp. 1-5, 2006.

[43] H. Kolsky, "Stress waves in solids," Journal of Sound and Vibration, vol. 1, no. 1, pp. 88-110, 1964. 